\title{
Filipe Melanchthon, reformador e humanista
}

\author{
Philip Melanchthon, reformer and humanist
}

Rubia Campos Guimarães Cruz $^{1}$

Resumo: A Reforma Protestante ocorrida no século XVI foi um marco na história do Cristianismo. Lutero foi um importante líder desse processo histórico e também aqueles que estiveram ao lado dele colaborando. Dentre as figuras dessa época, o presente artigo apresenta outro reformador de Wittenberg, Filipe Melanchthon. Nosso objetivo é mostrar como ele fez parte do movimento da Reforma através de importantes trabalhos que escreveu e também do auxílio a Lutero. Além disso, buscaremos apresentá-lo como um humanista e reformador educacional muito atuante no período histórico citado. Não há pretensão em se esgotar o assunto, mas tão somente trazer uma breve introdução a respeito desta figura histórica e alguns de seus feitos.

Palavras-chave: Reforma. Filipe Melanchthon. Reformador. Humanista. Educação.

Abstract: The Protestant Reformation (16th century) was a mark on Christianity's history. We have the consciousness that Luther was an important leader on the historical process, but we also know that many others were collaborating with him. Among the figures of that time, this article aims to present the other reformer of Wittenberg: Philip Melanchthon. The purpose of this article is to show how Melanchthon was part of the Reformation movement, through the important papers he wrote, as well as through the assistance he provided to Luther. However, we want to present him also as a humanist and educational reformer very active during this historical period mentioned. We do not mean to exhaust the subject; instead, we would rather bring a brief introduction about this historical figure and some of his deeds.

Keywords: Reformation. Philip Melanchthon. Reformer. Humanist. Education.

\section{Introdução}

Este artigo pretende refletir sobre a vida e as contribuições históricas de Filipe Melanchthon, personagem da Reforma Protestante ao lado de Lutero. Normalmente, quando se pensa no século XVI, e mais especificamente na Reforma, é comum associar

\footnotetext{
${ }^{1}$ A autora é mestranda em Ciência da Religião (UFJF), bolsista CAPES, com pesquisa na área de Filosofia da Religião. O presente artigo é resultado parcial da pesquisa de mestrado, bem como resultado da bolsa de Iniciação Científica - O REFORMADOR HUMANISTA FILIPE MELANCHTHON (BIC / UFJF), na qual a autora participa como voluntária. Contato: rubiacamposgc@gmail.com
} 
esse movimento à imagem de Lutero. Entretanto, outras figuras participaram desse processo histórico.

É nesse sentido, de pensar sobre essas outras figuras, que este artigo se situa. Aqui, focaremos em Melanchthon, o outro reformador de Wittenberg. O objetivo é mostrar que ele foi um humanista, mas também um reformador em dois aspectos, tanto no âmbito religioso quanto no âmbito educacional da Alemanha de sua época.

Se a história deixou esse personagem em segundo plano, nosso intuito aqui será justamente o de resgatar essa figura histórica e suas contribuições nas diferentes áreas do pensamento. Para isso, será apresentada, primeira, uma breve introdução sobre a Reforma Protestante e Lutero, em seguida, quem foi Melanchthon pontuando brevemente sobre seu nascimento e infância e por último, esse personagem tanto como reformad or quanto como humanista e reformador educacional.

\section{A Reforma Protestante e Lutero}

É assim que Carter Lindberg (2017, p.85) se refere à Reforma Protestante: “[...] um movimento oriundo da universidade [...]", isto é, como um movimento que teve seu estopim dentro de um centro de estudo e não de dentro da Igreja ou no meio da rua, mas de dentro da universidade. Para ele, a Reforma se beneficiou do "humanismo", abordagem "que lutou para aplicar a recuperação crítico-intelectual de formas antigas de educação, da Igreja e da sociedade como um todo" (LINDBERG, 2017, p. 85). Ou seja, "sem humanismo, sem reforma" (MOELLER, 1982, p. 36 apud LINDBERG, 2017, p. $85)$.

Foi na cidade de Wittenberg de 2.500 habitantes que tudo aconteceu. Conforme Lindberg (2017), ela era a capital do Eleitorado da Saxônia. Na época em que Lutero chegou nessa cidade, Frederico III, o sábio, era o príncipe. Foi este príncipe quem construiu em Wittenberg a universidade, motivo pelo qual Lutero (1483-1546) veio a residir na mesma. Ele começou a lecionar no inverno de 1513-14 e chegou a dar aulas de Salmos, Romanos, Gálatas e Hebreus na universidade, tendo uma boa biblioteca a seu dispor.

De acordo com Lindberg (2017, p. 93), “o estudo intenso de Lutero da língua e gramática bíblicas, auxiliado por ferramentas linguísticas disponibilizadas pelos 
humanistas do renascimento, mudou radicalmente seu entendimento da salvação". Foi neste contexto de estudo e de insatisfação pessoal que Lutero chegou a uma conclusão a respeito da justiça de Deus. Naquele momento, ele entendeu a Escritura: "O justo viverá pela fé" (BÍBLIA, Carta aos Romanos 1,17).

Conforme mostra Lindberg (2017), a experiência de conversão de Lutero fez com que a salvação não fosse mais vista como o objetivo da vida, mas sim como fundamento da mesma. Essa mudança, na forma como Lutero entendia a salvação, provocou uma reforma curricular na universidade de Wittenberg: a teologia escolástica foi substituída por estudos bíblicos.

A partir deste contexto, Lutero passa a criticar fortemente a prática das indulgências, algo que ele já criticava anteriormente. É assim que surgem as "Noventa e cinco teses". Essas teses eram claramente "proposições acadêmicas, típicas de um debate universitário, e foram escritas em latim, quando a maioria dos cidadãos de Wittenberg sequer lia alemão" (LINDBERG, 2017, p. 103). Para Lindberg, a imagem do jovem Lutero irritado, martelando as teses na porta da igreja é mais uma ficção romântica do que um fato histórico. Há um grande debate acerca do modo de exposição das teses: se elas foram pregadas na porta da catedral ou enviadas por correspondência. O fato é que o documento de debate causou uma grande repercussão. Isso ocorreu porque Lutero enviou o documento a Alberto, arcebispo de Mainz, para reclamar de Tetzel, um famoso vendedor de indulgências, que estava fazendo fortuna com esta ocupação, abusando da autoridade da Igreja.

Contudo, aind a conforme Lindberg, este mesmo documento foi enviado a Roma; o resultado foi uma explosão que assustou a todos. Lutero, "sem perceber, tocará em alguns pontos sensíveis da autoridade papal e em intrigas de vasta implicação política e eclesiástica" (LINDBERG, 2017, p. 103). Isso se dá a partir da data tradicional da Reforma, 31 de outubro de 1517. Uma ferrenha disputa se manifesta a partir deste momento em que, definitivamente, Lutero foi a causa, o líder deste movimento.

Se for verdade que a história escolhe seus heróis, no caso da Reforma o escolhido foi Lutero. No entanto, como se sabe, processos históricos não são feitos por apenas uma pessoa. De acordo com Ulrich e Klug (2016), muitos foram os homens e até mesmo as mulheres que estavam ao lado de Lutero nesta batalha. Um deles foi Filipe Melanchthon (1497-1560). Eles se conheceram em 1518 em um ambiente universitário. 
Naquele momento, Lutero havia encontrado um aliado para a empreitada que já havia se iniciado. Melanchthon foi, de acordo com Sinner (2018, p. 06),

(...) Único reformador a acompanhar o processo da Reforma do século XVI desde a sua incepção com as teses de Lutero contra as indulgências até a paz de Augsburgo de 1555, que selou a situação biconfessional da Europa central.

\section{Quem era Filipe Melanchthon?}

Felipe Schwartzerdt nasceu em 16 de fevereiro de 1497, Bretten, Alemanha. Era o primogênito do casal Georg Schwartzerdt e Barbara Reuter. Heinz Scheible (2013) aponta que Melanchthon passou a infância sem grandes perturbações, compartilhando a vida com seu irmão e suas três irmãs. Na escola, desde cedo, seu talento para línguas foi reconhecido, o que logo fez com que ele tivesse um professor particular.

Seu pai faleceu em outubro de 1508. Ele havia participado de uma guerra; voltou para casa em estado doente e sofreu quatro anos até sua morte. Nesse mesmo mês, faleceu também o seu avô. Aos onze anos, Melanchthon juntamente com seu irmão, foi enviado a Pforzheim para frequentar uma renomada escola de latim. Nessa cidade, ele se sentia muito bem, e foi ali que ele teve contato com Johannes Reuchlin ${ }^{2}$ - importante humanista ao lado de Erasmo, com quem aperfeiçoou seus estudos (SCHEIBLE, 2013).

Era um costume nos círculos humanistas da época batizar os estudantes com a forma latina ou grega do nome. Por conta disso, Reuchlin renomeia Filipe com o sobrenome Melanchthon "(schwarzeerde, cujo significado literal em alemão é terra preta)” (ULRICH; KLUG, 2016, p. 151). Segundo Ulrich e Klug (2016), essa mudança de sobrenome era um batismo humanista e significava que Filipe havia de fato entrado no mundo dos eruditos: não era apenas mais um aluno, mas sim alguém instruído que poderia ter um futuro nessa área.

Após o estudo das línguas clássicas, Reuchlin recomenda-o para a universidade de Heidelberg. Foi quando "recebeu o título de Bacharel em artes clássicas, em 10 de

\footnotetext{
${ }^{2}$ É controverso se eles eram parentes ou não; por exemplo, Ulrich e Klug (2016, p. 151) a pontam para o parentesco, mas Scheible (2013, p. 13) não o faz. Entretanto, o fato é que Reuchlin foi o patrono dos estudos de Melanchthon. Johannes Reuchlin (1455-1522), conforme Ulrich e Klug (2016) apontam, foi um dos humanistas mais conhecidos do norte da Europa, foi ele quem contribuiu grandemente para o estudo do hebraico bíblico e para a promoção da liberda de de investigação científica.
} 
junho de 1511" (ULRICH; KLUG, 2016, p. 152). Ainda na linha traçada por esses autores, vemos que Melanchthon em 1512 se muda para a universidade de Tübingen, onde recebe o título de Mestre em Artes. Com este título, passa a lecionar nessa universidade.

Posteriormente a Bretten, Pforzheim, Heidelberg e Tübingen, Melanchthon vai para Wittenberg. Como já dito, foi esta a cidade em que Frederico III, o sábio, construiu a universidade, a mesma em que Lutero estava. Scheible (2013) nos mostra que o príncipe-eleitor convidou Reuchlin para assumir a cátedra de grego. Ele não aceitou, mas recomendou seu aluno Melanchthon, com 21 anos nessa época.

Em agosto de 1518, Melanchthon chega à universidade e, no dia 28, profere seu famoso discurso de posse De corrigendis adulescentiae studiis (Reforma dos estudos dos jovens). Scheible aponta que, em seu discurso, Melanchthon se apresentou como paladino da Renascença, ou seja, alguém que desejava defender e propagar esse movimento. Além disso, prestigiou a tradição acadêmica: avaliou negativamente a alta escolástica; se mostrou contra o desprezo pela língua grega, a ignorância da matemática e o estado de abandono da teologia; deixou claro que tinha um programa reformador para o estudo dos jovens e que esse programa não procurava eliminar as disciplinas clássicas da época; e, por fim, elogiou a política educacional do príncipe-eleitor. (SCHEIBLE, 2013).

Segundo Sachiko Kusukawa (1995), nesse discurso, Melanchthon não fez nenhuma crítica à filosofia antiga em si, mas apontou que entendia que alguns textos de Aristóteles precisavam de uma reforma em seu ensino no que dizia respeito à tradução dos mesmos. Nesse ponto específico, mas também com todo discurso, Lutero ficou impressionado e encontrou em Melanchthon um amigo leal e um colaborador já que também desejava uma reforma no ensino escolástico, principalmente no uso de novas traduções para alguns textos de Aristóteles ${ }^{3}$. A autora ainda aponta que Melanchthon

\footnotetext{
${ }^{3}$ Conforme Kusukawa (1999) aponta, nas páginas xvi-xvii, o ataque de Lutero a Aristóteles era mais especificamente à forma como era ensinada sobre o filósofo e suas ideias nas Universidades do século XVI, não somente na Universidade de Wittenberg. No desejo de colocar o ensino bíblico em primeiro lugar, a mbos os reformadores defenderam que o ensino sobre Aristóteles fosse abolido. Entretanto, mais tarde, devido a alguns eventos da Reforma - mais especificamente de âmbito social e de fé, como os motins de Wittenberg em 1521 e 1522, a disputa com os profetas de Zwickau, a pregação sediciosa de Thomas Müntzer, e o surgimento dos a nabatistas - Melanchthon entendeu que o evangelho estava sendo ameaçado. Para ele, esses problemas eram todos devido a uma educação pobre e uma confusão entre filosofia e teologia. Por causa disso, decide retornar aos ensinamentos da filosofia para tentar sanar essa s
} 
também se sentiu atraído para a teologia de Lutero e rapidamente buscou seu diploma de Bacharel em Bíblia (Baccalaureus biblicus). Para conquistar o diploma, defendeu 24 teses sobre a justificação pela fé por incentivo de Lutero.

A partir desse momento, começou também a ensinar a Bíblia, fazendo preleções sobre alguns de seus livros. Ele tratou do Evangelho de Mateus e da carta aos Romanos. Quando Lutero se ausentou por conta de uma viagem, Melanchthon também assumiu as preleções dele, ensinando as cartas aos Coríntios e o Evangelho de João. (SCHEIBLE, 2013). Nessa época, uma parceria entre os dois foi firmada e a mesma se estenderia por longos anos.

\title{
3. Melanchthon, o reformador
}

De acord o com Lindberg (2017, p. 27-28):

\begin{abstract}
Reformadores encorajavam as pessoas a julgar todas as doutrinas pela Escritura; todas as igrejas, por sua vez, voltavam-se à história com o fim de legitimar e reforçar reivindicações individuais a respeito de serem a comunidade fiel. Os que estavam convencidos de que a igreja medieval consistia em uma corrupção total da igreja primitiva desenvolveram conceitos martirológicos para apoiar sua visão de que, a despeito de corrupção, havia ainda testemunhas fiéis ao movimento iniciado por Jesus na história.
\end{abstract}

Os reformadores do século XVI estavam insatisfeitos com o estado atual da Igreja medieval e intimamente interessados em revolucionar a mesma eliminando a corrupção e o que julgavam ser um ensino errado, principalmente no que dizia respeito a penitência e a salvação, redirecionando as pessoas para a doutrina da Escritura. Lutero desencadeou essa renovação religiosa na Alemanha de sua época e Melanchthon o acompanhou e o auxiliou.

O bacharelado de Melanchthon em Teologia fez dele um precursor dessa renovação religiosa que havia se iniciado. Lutero o reconhecia como ousado pela forma que enfatizava o princípio das Escrituras e criticava as doutrinas centrais da Igreja (SCHEIBLE, 2013). Todo estudo de Melanchthon, tanto das línguas clássicas quanto das Escrituras, foi crucial no desenvolvimento da Reforma e nos papéis por ele 
desempenhado durante esse processo. Em muitas das disputas ocorridas no período da Reforma, Melanchthon esteve presente e teve importantes participações. Essas disputas, bem como alguns assuntos sobre os quais se posicionou de maneira a defender os ideais da Reforma e os de Lutero, constam na biografia escrita por Scheible (2013).

Um exemplo ocorreu em Leipzig em 1519 na disputa de Karlstadt e Lutero contra Johannes Eck. Melanchthon constatou que os concílios poderiam incorrer em erros, o que representava uma novidade já que a Igreja era tida como a autoridade final em qualquer assunto. Naquele mesmo ano, ao escrever suas teses de bacharelado, Melanchthon tirou consequências relativas à ordenação de sacerdotes e à doutrina da transubstanciação o que, por sua vez, gerou uma acusação contra ele. Em fevereiro de 1520, se posicionou exigindo o livre debate acadêmico e passando a colocar a Escritura acima de todas as tradições - não como algo reservado aos teólogos, mas acessível a todos os cristãos - pontuando, ainda, que os concílios só deveriam ter autoridade se concordassem com a Escritura. Com esta afirmação, ele criticava à infalibilidade papal. (SCHEIBLE, 2013).

Melanchthon também implementou, em missas particulares, a Santa Ceia com ambos os elementos, pão e cálice, algo que para a época representou um grande espanto já que os fiéis, até então, só recebiam o pão. Para muitos, esta atitude representava um grande problema. Por conta disso, também buscou tratar esta questão a nível acadêmico, com debates sobre a missa. A mando do novo príncipe-eleitor João, Melanchthon visitou muitas paróquias na Turíngia com o objetivo de inspecioná-las e corrigir qualquer aspecto que fosse considerado errado com relação ao Evangelho pregado, errado de acordo com a ótica dos reformadores. Melanchthon também chegou a discutir sobre o batismo, indo ferrenhamente contra os anabatistas. (SCHEIBLE, 2013).

Citar esses eventos não esgota toda a participação de Melanchthon na Reforma, considerando que também teve participação em outros eventos importantes. No entanto, eles revelam parte de suas ações e dos debates que provocaram na época e mostram que, enquanto reformador, ele era ativo e engajado.

Um momento importante em meio a todos os acontecimentos foram os dias 16 a 18 de abril de 1521 na qual Lutero, por continuar escrevendo suas obras da reforma e desafiando a Igreja, "foi chamado para a reunião na cidade de Worms, para que se retratasse com relação às suas teses" (ULRICH; KLUG, 2016, p. 155). Este evento 
marcante da época da Reforma é atualmente conhecido como a "Dieta de Worms". Ulrich e Klug relatam que Lutero não se retratou, mas ficou firme em suas decisões, alegando que a Igreja Católica precisava de uma reforma, ou seja, de uma mudança de dentro para fora.

Diante disso, o imperador, que estava a favor da tradição da Igreja Católica, redigiu um édito declarando Lutero proscrito, isto é, herege. Após esta condenação, "Lutero ficou refugiado no castelo de Wartburg em Eisenach, até março de 1522, sob a proteção do príncipe Eleitor Frederico III" (ULRICH; KLUG, 2016, p. 155). Ele ficou ausente de Wittenberg por quase um ano. Durante este tempo, ainda conforme Ulrich e Klug, Lutero traduziu o Novo Testamento do grego para o alemão a partir do incentivo de Melanchthon. Esta, por sua vez, foi a primeira tradução feita diretamente do grego. Já existiam outras traduções, mas até então elas haviam sido feitas a partir de traduções latinas. Nesse período, Melanchthon permaneceu em Wittenberg lidando com os acontecimentos da Reforma e se correspondendo com Lutero até o seu retorno.

Lutero e Melanchthon eram companheiros nessa Reforma, mas não eram iguais em tudo e nem concordavam em todos os aspectos.

Ambos diferiam em diversos pontos - e certamente em termos de temperamento. Embora, em alguns momentos, Lutero ficasse impaciente com a "extrema" cautela de Melanchth on, e, em outros, Melanchthon se incomodasse com a irascibilidade de Lutero, as diferenças na personalidade de ambos não os separaram (LINDBERG, 2017, p. 121).

Como é possível observar, cada um possuía um jeito próprio de ser e de se manifestar. Lutero, como se pode inferir, era mais enérgico, alguém de mais ação, que estava disposto a lutar pela causa da forma que fosse preciso. Ele se reconhecia como "tosco, barulhento, tempestuoso e rude derrubador de mato" (RIETH, 1997, p. 224). Já Melanchthon apresentava uma natureza mais branda e grande conhecimento linguístico. Essa última característica foi muito bem reconhecida por Lutero que aponta Melanchthon como alguém que passa de "maneira refinada e calma, semeia e irriga com prazer" (RIETH, 1997, p. 224). A criação de Melanchthon fez dele um fino humanista, um importante conhecedor das línguas clássicas e um dedicado acadêmico. Nesse processo histórico, essas características foram de extrema importância uma vez que ele foi crucial para a escrita de alguns documentos importantes da Reforma dos quais se 
destacam os textos da Confissão de Augsburgo, Apologia da Confissão e os Loci Theologici (Tópicos teológicos) (GROSS, 2018).

Historicamente, sabe-se que a Confissão de Augsburgo foi apresentada diante do Imperador Carlos V que, em 1530, desejava resolver a questão religiosa entre católicos e protestantes. Para tanto, "pediu aos protestantes que apresentassem uma declaração de fé durante o encontro" (LINDBERG, 2017, p. 268). Esse mesmo autor, ao relatar tal episódio, aponta que em função da prescrição, Lutero era considerado um fora da lei e, por conta disso, não podia viajar. Então Melanchthon foi como representante. Uma série de rascunhos com os argumentos foram preparados semanas antes.

Ao chegar a Augsburgo, Melanchthon fica sabendo que Maier, representante católico, havia preparado 404 artigos que apontavam os reformadores como hereges. Logo, começou a trabalhar no material que havia levado visando responder ao ataque. Desse modo, "Melanchthon foi o autor principal da Confissão de Augsburgo" (LINDBERG, 2017, p. 268) juntamente com outros autores do grupo protestante. Conforme Altmann e Winterle destacam, este documento pretendia ser ecumênico e não separatista. O conteúdo deste texto é o seguinte:

\footnotetext{
Apresenta nos seus primeiros 21 artigos o que os luteranos crêem, conforme a fé que a Igreja cristã sempre creu e confessou durante toda a sua história. Dos artigos 22 a 28 , apresenta assuntos "sobre os quais há divergência”, em particular, abusos sanados na prática eclesial luterana (ALTMANN; WINTERLE, 2005, p. 05).
}

Ou seja, entre esses dois grupos existiam pontos de concordância e divergência e eles desejavam debater principalmente as diferenças, tentando encontrar um equilíbrio entre ambos. Para esses autores, o norte teológico da Confissão era claro: a "salvação gratuita que Deus realizou através do sacrifício e da ressurreição de Cristo e que nos é oferecida inteiramente de graça por Deus, mediante a fé em Jesus Cristo" (ALTMANN; WINTERLE, 2005, p. 05). Portanto, todos os pontos eram defendidos a partir dessa base comum.

Lindberg (2017) aponta que a Confissão foi lida para o imperador no dia 25 de junho e a leitura levou duas horas. No dia 3 de agosto, os católicos Maier e seus colegas apresentaram a Confutação, um documento que discordava da ideia dos reformadores. Foi exigido do grupo protestante o reconhecimento de que havia sido refutado, mas uma 
vez que não houve acordo entre as partes, os favoráveis à Confissão escreveram um documento conhecido como Apologia apresentado no dia 22 de setembro, ou seja, uma defesa extensiva do primeiro documento dos reformadores que Melanchthon também participou do processo de escrita. No entanto, "Carlos declarou o assunto fechado com a Confutação, recusando-se a aceitar a apologia”, destaca Lindberg (2017, p. 271).

Por fim, a divergência entre católicos e protestantes não encontrou uma solução e não houve acordo, ficando claro que o império de Augsburgo "teria de conviver com duas confissões" (LINDBERG, 2017, p. 271). Após todo esse episódio relatado por Altmann, Winterle (2005) e Lindberg (2017), a Confissão de Augsburgo, que Melanchthon foi um dos autores participantes, acabou se tornando o documento oficial e fundamental das Igrejas Luteranas até os dias de hoje. Lutero reconheceu o grande esforço do colega neste documento:

Li a Apologia [Confissão de Augsburgo] escrita pelo mestre Philip e ela muito me agrada. Não seria capaz melhorá-la ou alterá-la e, mesmo que pudesse, não seria apropriado. Não conseguiria tratar o tema de modo tão gentil e cuidadoso. (WA Br, 5, p. 319-320 apud LINDBERG, 2017, p. 268).

Fica evidente, portanto, a relevância de Melanchthon para o movimento, o reconhecimento do mesmo por Lutero e a fidelidade em oferecer uma boa prática de seus talentos por parte do próprio Melanchthon. Entretanto, documentos de importância paralela são os Loci Theologic, escritos pelo autor e publicados primeiramente no ano de 1521. Scheible (2013) é quem relata o nascimento desta obra.

Como graduado em Teologia, este título exigia que Melanchthon apresentasse preleções Bíblicas. A partir disso, “em suas preleções sobre a Carta aos Romanos, ele se deu conta de que essa obra-mor do apóstolo Paulo apresenta uma estrutura que ele, na qualidade de intérprete, precisava trazer à tona" (SCHEIBLE, 2013, p. 149). Assim, com base na Carta de Paulo aos Romanos, que nasceram os seus tópicos teológicos que vieram a ser uma importante obra que sistematizou a nova teologia nascente. É preciso ter em mente que os loci são um gênero literário e que Melanchthon se utiliza do mesmo para escrever sua obra. Os loci são tópicos ou lugar da argumentação. Sendo assim, ele aborda seus pontos teológicos por meio de tópicos e, portanto, por meio do gênero literário dos loci. Daí o nome da obra - Loci Theologici. 
Este era um gênero de ordenação textual. Conforme aponta Scheible (2013), o mesmo era muito utilizado pelos humanistas da época como Rudolf Agricola e Erasmo de Rotterdam. Era ensinado aos alunos anotarem a maior quantidade possível de loci para classificar o material lido. Ao ler diferentes autores, se faziam perguntas ao texto anotando os principais tópicos para, em seguida, ordená-los "por princípio da afinidade e do contraste" conforme explica Scheible (2013, p. 147). Esse era um meio dos jovens conseguirem "um estoque inesgotável de exemplos verbais e escritos" sendo que "o sistema desses loci eles mesmos pode[ria]m elaborar ou assumir de algum filósofo" (SCHEIBLE, 2013, p. 148).

Ainda nessa página, Scheible aponta que Erasmo chegou a recomendar esse tipo de ordenamento do texto também para o estudo da Bíblia. Os alunos que faziam uso desse tipo de gênero, ao final de seus estudos, tinham uma enciclopédia com diferentes tópicos e assuntos. O resultado era "uma coleção de materiais para comentário" em que "passagens obscuras se esclareceriam pela comparação com outras" (SCHEIBLE, 2013, p. 148).

Melanchthon, enquanto bom humanista utilizava-se desse gênero. Porém, ele pensou em uma "correlação objetiva dos conceitos com os temas. [...] Interconexão sistemática entre os loci” (SCHEIBLE, 2013, p. 148). Ou seja, ele não pensava apenas em ter um conjunto de tópicos isolados, mas um tópico que fosse correlacionado com o outro. Outro diferencial de Melanchthon com relação aos loci foi que, enquanto ele ensinava a carta aos Romanos, não fez perguntas ao texto para montar diferentes tópicos - o que era uma postura comum ao se utilizar esse gênero -, mas "tentou descobrir quais loci estão contidos no texto" (SCHEIBLE, 2013, p. 149) e os trouxe à tona, apresentando a estrutura dessa carta de Paulo em diferentes tópicos.

Melanchthon publica essa obra que visa abarcar a estrutura de Romanos “inicialmente em fascículos de agosto a dezembro de 1521" (SCHEIBLE, 2013, p. 149) com o título Loci theologici. Ela foi muito significativa para a época. Diferentes autores reconhecem a importância da mesma. Gross (2018) aponta que a primeira base da redação dos Loci foi a carta aos Romanos, e esse texto tratava-se:

[...] de uma edição que, por um lado, espelha as críticas à especulação escolástica do jovem humanista, ao mesmo tempo em que mostra uma adesão decisiva aos ideais reformatórios encarnados na posição de Lutero. A volta às fontes originais do cristianismo encontradas na 
Bíblia é a forma particular dessa síntese entre a formação humanista e a proposta de reforma da igreja (GROSS, 2018, p. 11).

Ou seja, esse primeiro esboço do texto reunia os pontos importantes para um humanista que era a crítica contra a escolástica ${ }^{4}$, algo que fica bem claro ao longo do texto e buscava apontar teologicamente para aquilo que Lutero e, consequentemente, o movimento reformador acreditavam e entendiam como correto.

Peterson (2012) também pontua a importância dos Loci, mostrando que esta obra foi reconhecida como a primeira teologia sistemática luterana, obra que recebeu de Lutero o elogio de "insuperável”. Lutero afirmava que os Loci são "um livro que, a meu ver, merece não apenas ser imortalizado, mas também incluído no cânon da Igreja" (LUTERO, 1972 apud PETERSON, 2012, p. 11, tradução nossa) ${ }^{5}$.

Scheible também reconhece a novidade e importância dessa obra ao dizer que “com esse lance genial aos 24 anos, ele apresentou a primeira descrição sistemática da teologia da reforma, ao mesmo tempo em que criava um novo gênero literário científico que teria muitos imitadores" (SCHEIBLE, 2013, p. 33). Ou seja, é mais um autor que reconhece a obra como uma descrição sistemática desta nova Teologia nascente que ainda trazia junto de si um novo gênero literário.

Esse escrito de Melanchthon no ano de 1521 não representava um texto acabado e finalizado; pelo contrário, constituía-se como uma obra aberta que ele foi melhorando e revisando ao longo de sua vida. Ele "revisou-a muitas vezes, como ele também fazia com seus outros compêndios. Acabou reescrevendo toda ela [em latim] três vezes, para finalmente redigir ele próprio uma versão alemã” (SCHEIBLE, 2013, p. 149). Sendo assim, há muitas revisões dos Loci. Preus (2014) aponta que os estudiosos dividem as edições dos Loci em três períodos principais: o primeiro até 1535; o segundo de 1535 a 1543; e a versão final, no ano de 1559.

Portanto, Melanchthon foi modificando tópicos e acrescentando ideias à medida que a Reforma se desenvolvia. Por isso, temos um texto final muito maior do que aquele do início (1521). Seu objetivo nunca foi que seu texto substituísse a Bíblia: antes, ele

\footnotetext{
${ }^{4}$ Preus (2014, p. 20) nos mostra que a escolástica era um movimento teológico que teve início no século XII e durou até a Reforma. Esse movimento enfatizava a articulação da doutrina cristã com a dia lética, a lógica e a dedução. Lutero criticava fortemente este tipo de teologia, e por consequência, Melanchthon também teceu críticas contra os mesmos.

5 Texto original: "a book which, in my judgment, deserves not only being immortalized, but also being included in the Church's Canon".
} 
deveria ser um auxílio para aqueles que desejassem lê-la e conhecê-la, entendimento compartilhado por Lutero que, "numa conversa à mesa, de acordo com Stupperich, (1996, p. 83) disse que quem desejava ser teólogo precisava ler, primeiramente a Bíblia e depois os Loci de Melanchthon” (ULRICH; KLUG, 2016, p. 154).

\section{Melanchthon, o humanista e reformador educacional}

Lindberg (2017, p. 28) explica que,

Humanistas aspiravam e lutavam pelo renascimento (Renascença) clássico e antigo da linguagem, educação, ciência, arte e igreja, a ssim como consideravam a Idade Média uma época bárbara; por isso, a arte medieval, por exemplo, era chamada "gótica". Essa caracterização humanista foi impulsionada não apenas por critérios estéticos e filológicos, mas também teológicos e religiosos.

Os humanistas buscavam um retorno do clássico e do antigo. Seu lema era ad fontes, ou seja, um retorno às fontes. Eles tinham um "senso de que o antigo é melhor" (LINDBERG, 2017, p. 28) e, por isso, pregavam um resgate de tudo aquilo que era antigo. E esse resgate se dava em todos os âmbitos: estéticos, filológicos, teológicos e religiosos.

No âmbito religioso, isto pode ser visto de forma efetiva no momento da Reforma: "Melanchthon caracterizou a Reforma como a era em que Deus estava chamando a Igreja de volta às origens" (FERGUSON, 1948, p. 52 apud LINDBERG, 2017, p. 28). Ou seja, era tempo de olhar para trás e perceber aquilo que deveria ser resgatado e também modificado na Teologia e na História da Igreja.

Melanchthon era um humanista. Isto pode ser constatado quando se olha para o início de sua vida e para o seu discurso de posse em Wittenberg, já vistos no texto. É ali que ele se apresenta como alguém que defende enfaticamente a Renascença, ou seja, alguém que carrega os ideais do humanismo renascentista. Porém, é necessário entender em que sentido pode-se dizer que Melanchthon era um humanista. Para este fim, os dicionários de Mora (1964) e Abbangano (2003) podem nos ajudar.

Mora (1964) aponta que o termo "humanismo" foi usado pela primeira vez em alemão e, posteriormente, em italiano. $\mathrm{O}$ humanista era aquele que se dedicava às artes liberais, dentro dessas a história, poesia, retórica, gramática e filosofia moral. Segundo o 
autor, o humanismo renascentista não é uma filosofia nem uma época filosófica, mas é, em parte, um dos elementos da atmosfera filosófica do final do século XIV e parte dos séculos XV e XVI que carrega consigo várias tendências desenvolvidas posteriormente (integral, socialista, liberal, existencialista, científico e outras). Já Abbangano (2003) diz que o humanismo pode indicar especificamente o movimento literário e filosófico que nasceu na Itália (séc. XVI), ou qualquer movimento filosófico que tem como fundamento a natureza humana, seus limites e interesses. Em seu significado mais básico, o humanismo é um aspecto fund amental do Renascimento.

Dentre as quatro bases do Humanismo elencadas por Abbangano, as que encontram correspondência com Melanchthon é, primeiramente, "o reconhecimento da historicidade do homem" (ABBANGANO, 2003, p. 519), ou seja, levar em conta os vínculos do homem com o seu passado, como a grande admiração pela Antiguidade em que se reconhece que nos textos antigos se encontra a verdade. Em segundo lugar, o "reconhecimento do valor humano das letras clássicas" (ABBANGANO, 2003, p. 519) que tem as boas artes como disciplinas que formavam o homem. Hoje em dia seriam as disciplinas humanísticas. Por último, é o "reconhecimento da naturalidade do homem" (ABBANGANO, 2003, p. 519): o homem é um ser natural, assim, o conhecimento da sua natureza é algo indispensável. Nestes termos, Melanchthon é um humanista no sentido de ser alguém que valoriza os estudos clássicos, o conhecimento das línguas e a filosofia natural.

Gross (2020) confirma que essas características fazem parte do humanismo de Melanchthon. Enfatiza essa admiração pela Antiguidade quando diz que "o humanismo no pensamento de Melanchthon se manifesta pela sua elevada apreciação da cultura, particularmente da retomada da produção cultural da Antiguidade" (GROSS, 2020, p. 101). Portanto, havia fortemente no pensamento de Melanchthon que a Antiguidade Clássica era melhor e que era preciso voltar a essas fontes para ter acesso ao verdadeiro conhecimento. Em paralelo a essa questão, Gross também cita a importância das línguas clássicas, "a faceta que melhor expressa o caráter humanista do pensamento de Melanchthon é o valor que ele dá ao estudo das línguas clássicas” (GROSS, 2020, p. 108). Desse modo, para um verdadeiro retorno à Antiguidade, era preciso ler nas línguas originais para que, de fato, a verdade contida nos textos fosse assimilada em toda sua completude. 
Nesse âmbito, valorizar as línguas clássicas é também valorizar o ensino de línguas (latim e grego, por exemplo), bem como o ensino das disciplinas que formavam o homem, e que eram essenciais para o enriquecimento da vida. Nesse sentido, Gross acrescenta que "ao tratar da organização do saber, ele critica a busca de conhecimento com o fim de obter uma carreira de sucesso" (GROSS, 2020, p. 101), ou seja, a educação não deveria ser associada meramente ao âmbito financeiro, mas ser vista como algo essencial à constituição humana e sua realização. Outra questão muito valorizada era a linguagem. Como explica Gross (2020, p. 109): “o que mais caracteriza para ele o estudo das humanidades. A linguagem é o modo como o pensamento e os ensinamentos humanos são transmitidos". Por isso tamanha importância da mesma, já que só através dela se tem acesso ao conhecimento.

Por fim, assim como no pensamento de outros humanistas, a retórica também tinha seu lugar de importância no pensamento de Melanchthon e "não simplesmente como domínio dos adornos aplicados à linguagem. Seu entendimento da disciplina da retórica era de que os conhecimentos que ela veiculava eram essenciais no processo interpretativo [...].” (GROSS, 2020, p. 102-103). Vemos aqui que o humanismo dele está completamente associado ao retorno à Antiguidade Clássica como meio para uma formação humana de qualidade.

O lado humanista de Melanchthon fez com que fosse extremamente preocupado com a educação em sua época. Por isso, além de ser professor na universidade de Wittenberg, também atuou visando uma reforma no ensino, o que nos permite vê-lo como um reformador educacional. Essa ação no âmbito educacional rendeu a ele o título de "Praeceptor Germaniae (Mestre da Alemanha), Der Lehrer Deutschlands (O Professor da Alemanha)" (ULRICH; KLUG, 2016, p. 150).

Scheible (2013) destaca que a Reforma trouxe consigo uma reivindicação humanística pela reforma do sistema educacional. Até então, a educação tinha como base a escolástica, influência predominante da filosofia aristotélica sobre a Teologia, com a qual os reformadores não concordavam. Sendo assim, eles buscaram promover a interpretação das escrituras bíblicas nas universidades, o que levou os alunos a abandonar outras áreas dos estudos - gramática, lógica, retórica - para assistir às aulas a respeito da Bíblia e da salvação. Por conta disso, Lutero e Melanchthon receberam uma carta manifestando a preocupação de que a teologia de Wittenberg prejudicasse as 
outras ciências. Em 1523, eles publicaram "A suprema necessidade dos estudos humanísticos para futuros teólogos" (SCHEIBLE, 2013, p. 35). A partir desse momento, passaram a visar alguns pontos importantes para a educação, principalmente Melanchthon que, segundo Ulrich e Klug (2016), via a grande importância do conhecimento científico, tendo implementado uma reforma universitária e também uma reforma escolar.

No âmbito universitário, os anos de 1523/24 foram significativos: Melanchthon foi eleito reitor da Universidade de Wittenberg. Ele aproveitou sua gestão para formular um novo regulamento de estudos que envolvia

[...] o desenvolvimento das habilidades linguísticas por meio de declamações e a implementação de um currículo estruturado de mo do a ajustar-se às necessidades individuais dos alunos mediante controle por instrutores (SCHEIBLE, 2013, p. 38).

De acordo com Scheible, através desse regulamento, o reitor encaminhava cada aluno para um pedagogo que iria planejar seu estudo pessoal. Além disso, o regulamento previa a conduta geral dos estudantes que deveriam "andar decentes, vestir-se com dignidade e cumprimentar seus superiores", estando proibidos de "forçar portas, devastar jardins, prostituição, bebedeira, panfletos difamatórios berreiros e tumultos na rua" (2013, p. 39).

Ainda segundo Scheible (2013), em 1526, a Faculdade de Filosofia adotou um regulamento de estudos elaborado por Melanchthon. Esse regulamento previa que para os alunos iniciantes era importante a formação gramatical com tutor, aulas de dialética e retórica a partir de compêndios de Melanchthon e matemática através do comentário de Proclo sobre Euclides. Já para os alunos que desejavam graduação como Magister ou desejavam as faculdades superiores, deveriam saber descrever com clareza assuntos das ciências naturais e da ética, estudar dialética e retórica a partir de Quintiliano, realizar o estudo de matemática e física em peso, buscar o aprendizado do grego e hebraico (principalmente para os teólogos) e participar de debates. (SCHEIBLE, 2013).

Nota-se que Melanchthon priorizava estudos voltados para gramática, línguas, matemática e prática de discursos e uma formação individual que levasse em conta os limites e possibilidades de cada estudante. Além de seu papel como reitor e dos regulamentos de estudos elaborados, também escreveu estatutos para as faculdades de 
Teologia e Filosofia (1545) e desempenhou funções na administração acadêmica da Faculdade de Teologia. Melanchthon nunca deixou a Universidade de Wittenberg, mesmo tendo recebido vários convites de outras universidades (SCHEIBLE, 2013).

Já no âmbito escolar, conforme apontado por Scheible (2013), Melanchthon buscou implementar uma boa didática para as escolas de latim. Ele dividiu essas escolas em três partes: na primeira as crianças aprendiam a ler e escrever e praticavam o canto; na segunda aprendiam gramática, música, tinham dever de casa (decorar uma sentença de algum autor) e ensino cristão uma vez por semana; na terceira, liam Virgílio, Ovídio, Cícero, aprendiam a escrever versos e eram orientados em dialética, retórica e música.

Uma ação muito forte de Melanchthon na reforma escolar se deu por meio de seus compêndios e de seu texto "Instrução para os Visitadores" que continha as instruções para estruturar uma escola de latim. Foi assim que a reforma escolar se espalhou pela Alemanha e parte da Europa. Scheible ressalta que Melanchthon "só tomava iniciativa quando era incumbido de visitação ou ao ser solicitado" (SCHEIBLE, 2013, p. 44).

Ainda no âmbito escolar, é possível dizer “que Melanchthon foi o 'inventor' da escola secundária, visando uma maior preparação para o estudo universitário" (ULRICH; KLUG, 2016, p. 163). A primeira escola nesse estilo foi estabelecida na cidade de Nürnberg que tinha uma relação muito próxima com Wittenberg. Scheible (2013) conta que Melanchthon foi convidado para ajudar na organização dessa escola e que foi pessoalmente para colaborar levando pessoas que também poderiam contribuir. Nessa escola, que era gratuita, só seriam aceitos alunos que tivessem sido treinados em gramática nas escolas comuns de latim:

\begin{abstract}
A nova escola deveria começar com a matéria da série superior da escola de latim e equiparar-se a uma Faculdade de Artes reformada no sentido humanista: dialética e retórica, clássicos latinos e poemas próprios, grego, matemática e música, em caráter facultativo ta mbém hebraico. Todas as semanas, os alunos deveriam apresentar exercícios escritos em prosa e verso. Também estavam previstos debates periódicos (SCHEIBLE, 2013, p. 48).
\end{abstract}

Melanchthon foi convidado para assumir a direção da escola, mas não aceitou. Após todo o trabalho, na abertura solene em 23 de maio de 1526, ele fez o discurso de inauguração proferido em latim Oratio in laudem novae scholae - "Discurso em louvor 
da nova escola" (SCHWAB, 1997, p. 108-117 apud ULRICH; KLUG, 2016, p. 166). Scheible (2013, p. 57) observa que, no que diz respeito à reforma escolar, "a influência de Melanchthon não se limitava à sua presença pessoal, mas suas ideias surtiram efeito em muitos lugares por meio de seus alunos e também seus escritos”.

Outro esforço muito interessante de Melanchthon no âmbito da educação foi à casa da família de Filipe Melanchthon e Katharina Krapp chamada Melanchthonhaus. Ulrich e Klug (2016) relatam que o príncipe eleitor da Saxônia, João Frederico, ao levar em conta a importância de Melanchthon para a universidade, mandou construir uma casa para Melanchthon e sua família com onze quartos e um jardim. Melanchthon passou a residir na casa com sua família, mas o diferencial foi que passou a receber os estudantes, criando uma escola doméstica onde "os estudantes moravam junto com o mestre e, logicamente, junto com a família” (ULRICH; KLUG, 2016, p. 157).

O dia na casa tinha uma moldura litúrgica: iniciavam a manhã com louvor a Deus, faziam refeições em conjunto, recebiam aulas de Melanchthon em latim e grego e praticavam a conversação em latim. A escola foi referência de um modelo humanísticoreformatório de educação, sendo que "os estudantes vinham de diferentes países. A casa de Melanchthon e Katharina era um local de encontro internacional, onde circulavam os mais diferentes conhecimentos" (ULRICH; KLUG, 2016, p. 157). Segundo os autores, a casa de Melanchthon influenciou diretamente na forma como ele concebia a educação e as práticas educativas. Em outras palavras,

Felipe Melanchthon foi ativo na reforma educacional e universitária por mais de 40 anos norteando o desenvolvimento do sistema educacional na Alemanha. Redigiu estatutos, constituições de muitas escolas e universidades, adaptando-as às novas ideias, oriundas da reforma religiosa e do humanismo. Aconselhou governantes por toda a Europa, e escreveu muitos livros, gramáticas e manuais de ensino. Como professor da Faculdade de Letras da Universidade de Wittenberg, sempre enfatizou o retorno às fontes, antigos escritos e o estudo das línguas (latim, hebraico e grego). As influências no processo educacional incentivadas por Melanchthon, estão base adas na Reforma e no Humanismo (ULRICH e KLUG, 2016, p. 167).

A partir de todos os seus esforços e feitos, percebe-se que, para Melanchthon, a educação era um ponto crucial da vida em sociedade. Sendo assim, a mesma deveria ser voltada para a construção humana e não apenas uma educação para títulos, status, sucesso e ganhos financeiros. Para ele, a educação deveria ser valorizada e melhorada. 


\section{Considerações Finais}

No contexto acadêmico brasileiro, Melanchthon é ainda pouco conhecido ${ }^{6}$. Infelizmente, no âmbito historiográfico, ele foi um personagem deixado às sombras. Quando se pensa na Reforma, automaticamente lembra-se de Lutero e muitas vezes não há informações acerca do outro reformador de Wittenberg.

Em vista disso, este breve artigo buscou situar a figura de Melanchthon no período da Reforma (século XVI). Foi possível perceber que ele foi importante ao lado de Lutero, tendo atuado em muitos debates da época. Na ausência de Lutero, foi ele quem esteve em Wittenberg buscando preservar os preceitos da Reforma, além de ser o autor de muitos documentos importantes dessa época como a Confissão de Augsburgo, Apologia da Confissão e os Loci Theologici. Uma vez que se importava com a Igreja, com as práticas e ensinos de cunho religiosos, atuou fortemente em prol da renovação da mesma.

Além de reformador e, antes mesmo de poder ser considerado nesse âmbito, Melanchthon foi um importante humanista em sua época. Desde cedo, recebeu uma educação voltada a essa área. Enquanto humanista, se importava com os estudos clássicos, o conhecimento das línguas e a filosofia natural. Em vista disso, se preocupou e se ocupou com a educação de sua época, o que lhe rendeu o título de "Professor da Alemanha" (Praeceptor Germaniae). Deu aulas de línguas e de Bíblia na universidade de Wittenberg e, além disso, implementou reformas que visavam a melhoria do ensino tanto no âmbito universitário quanto no âmbito educacional.

Portanto, Melanchthon é uma figura histórica que merece ser conhecida. Sua vida e seus escritos podem trazer contribuições tanto para o âmbito religioso quanto para o educacional. Obviamente, ele apresenta limitações e defasagens em cada uma dessas áreas que refletem o pensamento próprio de sua época, mas muitas de suas ideias podem nos servir hoje, como por exemplo, na área da educação. Nosso objetivo foi

\footnotetext{
${ }^{6}$ No âmbito acadêmico brasileiro, atualmente temos uma dissertação sobre Melanchthon, intitulada: Filipe Melanchthon (1497-1560): Vida, Teologia e Figura do Outro Reformador de Wittenberg, cujo autor é Paulo Samuel Albrecht; orientador: Luís Corrêa Lima - 2013, da PUC-Rio. Em segundo lugar, podemos citar o esforço considerável do professor doutor Eduardo Gross (UFJF) em resgatar a figura desse reformador. Gross tem escrito vários artigos sobre Melanchthon, bem como, nos últimos anos proporcionou duas Iniciações Científicas sobre Melanchthon, no departamento de Ciência da Religião da UFJF.
} 
apresentar esse reformador e humanista, visando contribuir para a sua propagação nos estudos de religião no Brasil, bem como apontá-lo como uma nova possibilidade de pesquisa no âmbito da Ciência da Religião.

\section{Referências Bibliográficas}

ABBANGANO, Nicola. Dicionário de filosofia. $5^{\text {a }}$ ed. São Paulo: Martins Fontes, 2003, p. 518-519.

AltMAnN, Walter; WINTERLE, Carlos. A Confissão de Augsburgo, edição comemorativa 1530-2005. In: Comissão Interluterana de Literatura. São Leopoldo: Editora Sinodal; Porto Alegre: Editora Concórdia, 2005.

BÍBLIA SAGRADA. Traduzida por João Ferreira de Almeida. Revista e Atualizada no Brasil. Edição Revista e Atualizada no Brasil, $3^{\mathrm{a}}$ ed. (Nova Almeida Atualizada). Barueri, SP: Sociedade Bíblica do Brasil, 2018.

FERRATER MORA, José. Diccionario de filosofia. $5^{\mathrm{a}}$ ed. Buenos Aires:

Sudamericana, Tomo I, 1964, p. 875-878.

GROSS, Eduardo. A apreciação da literatura no humanismo teológico de Filipe Melanchthon. In: Pandaemonium. São Paulo, v. 23, n. 41, 2020, p. 95-124.

GROSS, Eduardo. Filipe Melanchthon, Loci theologici: tópicos teológicos de 1521. [editado e traduzido por] Eduardo Gross. Ed. crítica, bilíngue. São Leopoldo: Sinodal; EST, 2018.

KUSUKAWA, Sachiko. The Transformation of Natural Philosophy: The Case of Philip Melanchthon. Cambridge: Cambridge University Press, 1995.

LINDBERG, Carter. História da reforma. Tradução Elissamai Bauleo. $1^{\mathrm{a}}$ ed. Rio de Janeiro: Thomas Nelson Brasil, 2017, p. 450.

MELANCHTHON, Filipe. Orations On Philosophy and Education. (KUSUKAWA, Sachiko, Ed.). Cambridge: Cambridge University Press, 1999.

MELANCHTON, Filipe. Apologia da Confissão, de 1531. In: Livro da Concórdia As confissões da Igreja Evangélica Luterana, 1580. Ed. Sinodal; Concórdia; Ulbra, $7^{\text {a }}$ edição, 2006.

PREUS, Christian. Commonplaces: Loci Communes 1521. Introduction. Transl. Christian Preus. Saint Louis: Concordia, 2014.

RIETH, Ricardo Willy. O pensamento teológico de Filipe Melanchthon (1497-1560). São Leopoldo: EST. v. 37, n. 3, 1997, p. 223-235. 
SHEIBLE, Heinz. Melanchthon: uma biografia. São Leopoldo: Sinodal, 2013.

SINNER, Rudolf Von. Apresentação. In. Loci theologici: tópicos teológicos, de 1521; [editad o e traduzido por] Eduardo Gross. Ed. crítica, bilíngue. São Leopoldo: Sinodal; EST, 2018.

ULRICH, Claudete Beise; KLUG, João. Felipe Melanchthon (1497-1560): pedagogo da Reforma protestante, patrimônio da educação. São Paulo: Revista Brasileira de História das Religiões, ANPUH, Ano VIII, n. 24, 2016. 